\title{
Iron, type 2 diabetes mellitus, and Alzheimer's disease
}

\author{
Luca Mascitelli · Francesca Pezzetta • \\ Mark R. Goldstein
}

Received: 28 March 2009/Revised: 11 May 2009/ Accepted: 9 June 2009/Published online: 2 July 2009

(c) Birkhäuser Verlag, Basel/Switzerland 2009

Götz et al. [1] analyzed common clinical and biochemical features between type 2 diabetes mellitus (T2DM) and Alzheimer's disease (AD). However, among the suggested common pathogenic mechanisms between these disorders, they did not appear to mention the role of iron.

Iron is a strong pro-oxidant which catalyzes several cellular reactions that yield reactive oxygen species. This property, while essential for its metabolic functions, makes iron potentially hazardous. Indeed, the amount of free iron available at sites of oxidative or inflammatory injury appears to be a function of the stored iron level.

Accumulating evidence suggests that iron plays a pathogenic role in T2DM and its complications such as microangiopathy and atherosclerosis $[2,3]$. In addition to the induction of oxidative stress, iron may also impede insulin extraction in the liver, impair pancreatic insulin secretion, and interfere with insulin action and glucose uptake in adipocytes. Of note, a reduction in iron overload with either phlebotomy or iron chelation therapy has been shown to reverse or improve glycemic control in T2DM [2].

On the other hand, it is well known that neurons are not only vulnerable to impaired iron metabolism as a result of a reduced iron supply, but also that abnormal high cellular iron levels may lead to disordered neuronal function. In particular, an important pathological finding of $\mathrm{AD}$ is the iron accumulation that occurs in the same brain regions characterized by amyloid $\beta$ peptide deposition [4]. In fact, a potential pathogenic role of iron in AD has been recently suggested [5].

Therefore, by studying the role of iron in both T2DM and $\mathrm{AD}$, we might be able to increase our understanding of these disorders and develop new therapeutic strategies aimed at iron depletion.

\section{References}

1. Götz J, Ittner LM, Lim YA (2009) Common features between diabetes mellitus and Alzheimer's disease. Cell Mol Life Sci 66:1321-1325

2. Swaminathan S, Fonseca VA, Alam MG, Shah SV (2007) The role of iron in diabetes and its complications. Diabetes Care 30:19261933

3. Rajpathak SN, Crandall JP, Wylie-Rosett J, Kabat GC, Rohan TE, Hu FB (2009) The role of iron in type 2 diabetes in humans. Biochim Biophys Acta 1790:671-681

4. Zecca L, Youdim MB, Riederer P, Connor JR, Crichton RR (2004) Iron, brain ageing and neurodegenerative disorders. Nat Rev Neurosci 5:863-873

5. Silvestri L, Camaschella C (2008) A potential pathogenetic role of iron in Alzheimer's disease. J Cell Mol Med 12:1548-1550

\author{
L. Mascitelli $(\bowtie)$ \\ Medical Service, Comando Brigata alpina "Julia”, Udine, Italy \\ e-mail: lumasci@libero.it \\ F. Pezzetta \\ Cardiology Service, Ospedale di Tolmezzo, Tolmezzo, Italy \\ M. R. Goldstein \\ Fountain Medical Court, Bonita Springs, FL, USA
}

